\title{
Students' agency, creative reasoning, and collaboration in mathematical problem solving
}

\section{Ellen Kristine Solbrekke Hansen ${ }^{1}$ (D)}

Received: 3 July 2020 / Revised: 23 December 2020 / Accepted: 13 January 2021 /

Published online: 11 March 2021

(c) The Author(s) 2021

\begin{abstract}
This paper aims to give detailed insights of interactional aspects of students' agency, reasoning, and collaboration, in their attempt to solve a linear function problem together. Four student pairs from a Norwegian upper secondary school suggested and explained ideas, tested it out, and evaluated their solution methods. The studentstudent interactions were studied by characterizing students' individual mathematical reasoning, collaborative processes, and exercised agency. In the analysis, two interaction patterns emerged from the roles in how a student engaged or refrained from engaging in the collaborative work. Students' engagement reveals aspects of how collaborative processes and mathematical reasoning co-exist with their agencies, through two ways of interacting: bi-directional interaction and one-directional interaction. Four student pairs illuminate how different roles in their collaboration are connected to shared agency or individual agency for merging knowledge together in shared understanding. In one-directional interactions, students engaged with different agencies as a primary agent, leading the conversation, making suggestions and explanations sometimes anchored in mathematical properties, or, as a secondary agent, listening and attempting to understand ideas are expressed by a peer. A secondary agent rarely reasoned mathematically. Both students attempted to collaborate, but rarely or never disagreed. The interactional pattern in bi-directional interactions highlights a mutual attempt to collaborate where both students were the driving forces of the problem-solving process. Students acted with similar roles where both were exercising a shared agency, building the final argument together by suggesting, accepting, listening, and negotiating mathematical properties. A critical variable for such a successful interaction was the collaborative process of repairing their shared understanding and reasoning anchored in mathematical properties of linear functions.
\end{abstract}

Keywords Agency $\cdot$ Collaboration $\cdot$ Reasoning $\cdot$ Shared understanding

Ellen Kristine Solbrekke Hansen

ellen.hansen@nmbu.no

1 Department of Learning and Teacher Education, Norwegian University of Life Sciences

NMBU, P.O. Box 5002 NMBU, 1432 Ås, Norway 


\section{Introduction}

Students' mathematical communication, reasoning, and problem-solving are highlighted in the research literature as important aspects for fostering students' learning of mathematics (Pijls \& Dekker, 2011; Seidouvy \& Schindler, 2019; Sidenvall, 2019). Therefore, promoting students' mathematical communication such as making reasoning meaningful to oneself and peers, listening to one another, and solving mathematics together (Mueller et al., 2012) are central issues for progress in their mathematical understanding. Students' collaboration and reasoning are key interactional aspects in math-talk and small group work. It is a well-researched area but still highlighted as a topic where more knowledge is needed, because when students are given the opportunity they can construct their own solution procedures, important for their mathematical understanding (cf., Lithner, 2017; Mueller et al., 2012; Stockero et al., 2019).

Collaboration in classrooms has often been studied as an outcome or as a process (Dillenbourg et al., 1996). A research approach on the outcome is often seen as an individual's activity with focus on learning (Child \& Shaw, 2018; Dillenbourg et al., 1996), whereas a research approach on collaborative processes emphasize the whole group and in particular the participant interaction (Seidouvy and Schindler, 2019). With the latter view on collaboration, this study defines collaboration as "a coordinated, synchronous activity that is the result of a continued attempt to construct and maintain a shared conception of a problem" (Roschelle \& Teasley, 1995, p. 70). With this focus, the study views productive collaboration enacted when students build and maintain a shared conception of a mathematical problem, which is their shared understanding of the problem at hand (Roschelle \& Teasley, 1995). Moreover, for students to pool their knowledge together for a shared understanding, the study sees the processes of building by introducing and accepting knowledge, monitoring ongoing activity, and repairing conflicting interpretations, as central activities for such interaction.

Opportunities for studying situations of collaborative processes are in this study viewed through a problem-solving session, emphasizing active engagement in a learning process (Lithner, 2017). An active learning process is not common in so-called easier learning processes where solution procedures are imitated but rather found in students' problem solving when they attempt to construct their own solution procedures through reasoning (Lithner, 2017). Mathematical reasoning is a central interactional aspect of learning mathematics where arguments are important for the learning process and not only as an outcome of learning mathematics (Yackel, 2001). Therefore, this study views mathematical argumentation and reasoning as an interactional accomplishment and what students "take as acceptable, individually and collectively, and not whether an argument might be considered mathematically valid" (Yackel, 2001, p. 6). In line with this view, including all students at any competence level in mathematics, is Lithner's framework of mathematical reasoning (Lithner, 2008, 2017). From this framework, a student's reasoning is explained as "the line of thought adopted to produce assertions and reach conclusions in task solving" (Lithner, 2017, p. 939). 
In situations of mathematical communication, a student may become a producer of mathematics through their own and joint processes of grappling and exploring mathematics, sometimes hitting the wrong trail, and sometimes making sense of solutions, rather than being a reproducer (Freudenthal, 1991; Schoenfeld, 2013). Schoenfeld (2013) says: "A major issue is, when if ever do students get to develop a mathematical voice? That is, when do they get to propose ideas and answers, defend them, and become recognized as producers of mathematics themselves?" (p. 613). If these situations of mathematical communication include mathematical talk between students, they are in a student-student interaction. How well students interact in pairs and small groups is important for students' progress in becoming a mathematical producer, rather than an imitator who reproduces mathematics without understanding the conceptual parts (Lithner, 2017). Varhol et al. (2020) researched student interactions and found that some specific types of interactions were important for making mathematical progress in algebraic generalization. That study, and other studies on students' group work or pairwise collaboration, contends that quality student interactions and the dynamics of the processes in students' collaborations need to be further explored (Seidouvy \& Schindler, 2019; van de Pol et al., 2018; Varhol et al., 2020).

Students engage with one another and take on different roles while interacting. Sometimes a student leads the conversation, other times he or she might listen or withdraw from the conversation. Thus, roles in collaborative work can "change from moment to moment" (Child \& Shaw, 2018, p. 1). Hence, another central interactional aspect in group work, when considering students' actions and engagement in reasoning and collaboration, is students' exercised agency (Mueller et al., 2012). This study see agency as Gresalfi et al. (2009) define it; "the way in which he or she acts, or refrains from acting, and the way in which her or his action contributes to the joint action of the group in which he or she is participating" (p. 53).

The field needs a better understanding of peer interaction patterns in collaborative mathematical activity. Little is known about the dynamics of students' collaborative interaction in mathematics classroom, and few studies have taken the process view of collaboration (Seidouvy \& Schindler, 2019). This study focuses on three particular aspects of students' interactions: collaborative processes, mathematical reasoning, and exercised agency. To investigate conditions for fruitful collaboration, Kuhn (2015) states that "it is essential to understand the underlying mechanisms" (p. 47). Studying interactional aspects separately and seen in interplay in students' interaction patterns may therefore give a better understanding of underlying processes of collaboration, which can furthermore enable collaborative aspects to become teachable. Research on collaboration (Child \& Shaw, 2018; Kuhn, 2015) and reasoning (Lithner, 2017) argues that learning is enacted in both instances and that there is a need for insights of the underlying processes causing this learning opportunity. Therefore, unpacking students' social interactions found in the interplay of specific interactional aspects can make collaboration and reasoning more manageable for teachers and students, and consequentially promote productive quality interactions for learning opportunities in mathematics classrooms.

The aim of this study is to give detailed insights of interactional aspects with upper secondary students' roles in their collaboration and reasoning, when 
attempting to solve a linear function task together. With this aim, the research question is What are the patterns of interaction for creating a shared understanding through the interplay between students' creative reasoning, collaboration, and exercised agency in a mathematical problem-solving session?

\section{Theory}

\section{Mathematical reasoning}

Mathematical reasoning can be defined as "the explicit act of justifying choices and conclusions by mathematical arguments" (Boesen et al., 2014, p. 75). In line with this statement is the framework Creative mathematically founded reasoning ${ }^{1}$ (CMR, Lithner, 2008), which identifies two major types of reasoning: creative reasoning and imitative reasoning. The latter reasoning type is seen in students' use of remembered facts and memorized algorithms without considering their meaning. Such path of reasoning has its strength in quickly solving tasks in school mathematics. However, without the conceptual part it may lead to rote learning (Lithner, 2017). Creative reasoning, on the other hand, has the strength of promoting deeper understanding of mathematical procedures and concepts (Lithner, 2008). If engaged with creative reasoning, students are considering mathematical properties with the task they are solving or discussing, which makes it likely to develop an understanding (Lithner, 2017). Creative reasoning is characterized by three aspects: creativity, plausibility, and anchoring. These three aspects are interconnected in reasoning as follows: A student may create a new idea or recreate a forgotten one (creativity) using arguments which are meaningful and logical to the student who is employing them (plausibility) and that are based on mathematical properties (anchoring). Creativity is therefore a student's attempt to create or recreate a reasoning sequence that, to some extent, is new to them. A student's reasoning, expressed as arguments, is creative when supported by plausible arguments. Plausible arguments are explanations of strategy choices, implementations of the strategies, and explanation of why a strategy or solution will work or not (Olsson, 2018). The arguments are creative when explanations and suggestions are mathematically anchored justifications (Granberg and Olsson, 2015). Lithner (2008) explains the difference in mathematical property as superficial or intrinsic: "In deciding if $9 / 15$ or $2 / 3$ is larger, the size of the numbers $(9,15,2$ and 3$)$ is a surface property that is insufficient to consider while the quotient captures the intrinsic property" (p. 261). Central CMRcomponents are presented in Table 1.

\footnotetext{
1 In line with Lithner $(2008,2017)$ and his colleagues studying creative mathematically founded reasoning, this study uses the wording creative reasoning or acronym CMR for linguistically simplicity.
} 
Table 1 Overview of central elements of creative reasoning

Creative mathematically founded reasoning (CMR)

\begin{tabular}{lll}
\hline Creativity & Plausibility & Anchoring \\
\hline $\begin{array}{l}\text { New idea } \\
\text { Recreating a forgotten idea }\end{array}$ & $\begin{array}{l}\text { Explanation of strategy choice } \\
\text { Explanation of strategy implementation } \\
\text { Explanation of why something is true }\end{array}$ & $\begin{array}{c}\text { Ideas connected to mathematical } \\
\text { properties and concepts } \\
\text { Intrinsic: mathematical concepts and } \\
\text { properties }\end{array}$ \\
\hline
\end{tabular}

\section{Collaboration}

When students work together and attempt to do thinking together, their "emergent interplay of ideas" (Martin \& Towers, 2015) promotes a shared understanding of the problem. A shared understanding is students' collaborative outcome from engaging in collaborative processes where two or more students work together to solve a problem and attempt to produce a joint outcome (Roschelle and Teasley, 1995). In line with a view on students' merging of ideas into a shared conception for solving a mathematical problem, Roschelle and Teasley (1995) define collaboration as a "coordinated, synchronous activity that is the result of a continued attempt to construct and maintain a shared conception of a problem" (p. 70).

The way students engage in collaborative processes relates to how well collaboration is maintained and fostered (Child \& Shaw, 2016), and collaborative processes are important to study in students' interactions for the dynamics of joint mathematical problem solving. Students' attempts to create and uphold a shared understanding, through coordination of language and actions (e.g., Baker, 2015; Roschelle \& Teasley, 1995; Sarmiento \& Stahl, 2008), entail what Roschelle \& Teasley (1995) call collaborative processes of building, monitoring, and repairing. The collaborative process building means to suggest ideas to initiate collaboration or it could be a continuation or ending of collaborative work (Alrø \& Skovsmose, 2004; Child \& Shaw, 2018; Roschelle \& Teasley, 1995). For instance, if a peer accepts the suggested idea, such as a problem-solving strategy or implementation of an algorithm, a student contributes to build a shared understanding. A student could also read out loud and point at the problem to be solved. Sometimes, a peer listens to a suggestion or asks questions about an idea, which is important for monitoring a groups' shared understanding (Roschelle \& Teasley, 1995). A question about an idea might result in a monitoring action, such as an explanation. If an explanation does not make sense or a suggested idea seems wrong to a peer, then students might experience a discrepancy between viewpoints (Dillenbourg, 1999). But if students try to restore their shared understanding about the problem, they are in the collaborative process of repairing (Roschelle \& Teasley, 1995). Therefore, important actions for repairing a shared understanding are negotiations and corrections of conflicting interpretations, such as paraphrasing or repeating an utterance in one's own words (Alrø \& Skovsmose, 2004).

Through these processes, coordination is seen as mutual exchange of utterances and taken actions, e.g., hand gestures, inputs to a dynamic software program, and 
explanations and justification of mathematical ideas. Students need to engage in a mutual exchange of ideas and actions to access each other's thinking. In conversations, students can take turns suggesting, questioning, and negotiate ideas. Therefore, a central interactional practice in conversations is turn-takings (Roschelle \& Teasley, 1995; Sidnell, 2010). Turn-takings may therefore promote students' co-construction of a shared understanding through processes where students build, monitor, and repair the meaning or a strategy for solving a problem (Roschelle \& Teasley, 1995).

Trying to fix the differences in opinions (repairing), understanding an explanation (monitoring), or introducing ideas and suggestions as well as accepting them (building) are important social interactions co-existing with students' mathematical reasoning (Granberg \& Olsson, 2015). Components of the collaborative processes are presented in Table 2.

\section{Agency}

A student can participate in group work by contributing with ideas or by listening to peers. The participation may include actively seeking to solve the task at hand, by making their own attempts, which involves guesses, trials and wrong paths, and investigations that may lead to evaluating their own mathematical production (Freudenthal, 1991). However, another student or the same student, in a different situation or in a different group, could refrain from making suggestions and actions, or active listening. A student may, for various reasons, resist to attend to a collaborating peer. Therefore, the nature of a student's exercised agency will vary within different interactions and situations (Gresalfi et al., 2009).

There are several possible perspectives to study when focusing on students' exercised agency in mathematics. Carlsen, Erfjord, Hundeland, and Monaghan (2016) point to how different cultures, people, and artifacts shape students' actions and decisions, and thus, their exercised agency. Gresalfi et al. (2009) are concerned with students' engagement in classroom activities. This focus concerns students' act of complying or refraining (Sengupta-Irving, 2016), as well as about the given opportunities to act, either from a peer or from a teacher (Langer-Osuna, 2018). The latter aspect concerns distribution of agency (Gresalfi et al., 2009). A teacher may distribute agency through his or her authority to the given group (Engle \& Conant, 2002), or there could be a social conflict between group members, consequentially inhibiting students' talk and activities (Langer-Osuna, 2018).

Table 2 Overview of central elements of collaborative processes

Collaborative processes for building and maintaining a shared understanding

\begin{tabular}{lll}
\hline Building & Monitoring & Repairing \\
\hline Accepting ideas & Asking questions & Negotiations \\
Making suggestions & Explaining an idea & Correcting conflicting interpreta- \\
Stating a problem & Observing and responding to one & tions \\
Pointing out mathematical & another's interpretations and ideas & Counter-suggestions \\
properties & & Reformulations \\
\hline
\end{tabular}


The mentioned aspects of teacher authority, social conflicts, or different cultures and artifacts are relevant for studying students' collaboration and mathematical reasoning. However, to focus the agency aspect on student-student interaction, this study views students' exercised agency as their engagement in participation for making mathematical arguments or refraining from making mathematical arguments (Gresalfi et al., 2009).

To investigate students' argumentation when collaboratively solving mathematical problems, a framework on how students' agency is expressed in discursive practices (Mueller et al., 2012) is adopted. This framework is based on the definition on agency from Gresalfi et al. (2009) and suggests that students may exercise different agencies, such as shared agency, primary agency, or secondary agency (Mueller et al., 2012). See Table 3 for an overview of central elements of agency.

A shared agency is students' co-construction of arguments, where all participants contribute with their ideas. Therefore, ideas, suggestions, and actions are all important elements to building an argument from the ground, and only existing because of all the participants' contributions (Mueller et al., 2012). Contrasting shared agency is students' individual agency, where students are either a primary agent or a secondary agent. A student may act with primary agency when he or she makes the final argument based on correction from a peer or assimilates a peer's argument, or by making sense of a peer's faulty or flawed idea. A secondary agent makes inputs influencing the original argument. These inputs are either corrections or extended or flawed arguments, formed by the primary agent to a final argument (Mueller et al., 2012).

\section{Methods}

The study is characterized as an instrumental case study (Stake, 2003) — an in-depth study of the particular case of four student pairs, to advance the understanding of an interplay between students' creative reasoning, collaborative processes, and exercised agency.

\section{Data collection and participants}

This article reports on four pairs of students, age 15-16, who collaboratively worked on a function task (Fig. 1). The students were enrolled in their first year of a

Table 3 Overview of central elements of agency

\begin{tabular}{lll}
\hline Agency & & \\
\hline Shared agency & Primary agent & Secondary agent \\
\hline Co-construction of arguments & $\begin{array}{l}\text { Makes the final argument } \\
\text { Assimilates another student's argu- } \\
\text { ment } \\
\text { Makes sense of a peer's faulty or } \\
\\
\text { flawed argument }\end{array}$ \\
\hline
\end{tabular}


theoretical mathematics program. Data was collected in a Norwegian upper secondary school in 2017, where three mathematics classes (69 students altogether) and their three teachers participated.

In the design process of the larger study, which this case is a part of, the three teachers and the researcher (author) planned and evaluated lessons together emphasizing collaborative work and math-talk. Both prior to and after the planned lessons, the teachers and researcher discussed how to assist and interact with the students in order to promote mathematical reasoning and collaborative work. Students worked together in the same pairs over five consecutive months in their regular classroom setting. Based on the teacher-researcher conversations, the teachers attempted to ask open-ended questions with minimum guiding intervention, aiming to provide students with opportunities to make connections between function representations for understanding the function concept together. The three teachers were considered ordinary and engaged teachers, but not particularly used to organize classrooms for collaborative interactions. Hence, they were previous to the study not particularly aware of their teacher approach to support student pairs or whole classroom discussion for collaborative inquiries. This was a deliberate choice for the study, which this case study is a part of.

The students were organized into 33 pairs based on the following criteria: (1) reasoning competence; (2) understanding of functions; and (3) likeliness to engage in math-talk with one another. The two first criteria were based on the students' scores on a mathematics test. The last criterion was based on conversations with the teachers when considering point 1 and 2 .

Due to practicality of observing students through video recordings, two pairs in each of the three classrooms were set as a condition. For an in-depth analysis of interactional aspects in students' collaboration, six pairs were chosen. The six pairs were chosen based on the three criteria above, where two aspects particularly stood out: (1) students should express a high level of reasoning competence, which meant that they attempted to explain their thinking and anchored it in mathematics and (2) the likeliness of student pairs to be verbal and share thoughts with one another. These aspects were discussed with their teachers when making the pairs.

Two out of six student pairs did not exercise turn-takings, a criterion considered important for creating a shared understanding of the problem. These two pairs did not have successful conversations, since they were not engaged in sharing thoughts with one another. The four other student pairs exercised interactions with reasoning, collaborative processes, and different agencies. From the analysis ("Data analysis"), two distinct ways of interacting were seen, two pairs within each interaction pattern.

- Create a straight line $y=m x+c$

- Create another straight line in a way that the corresponding graphs are perpendicular.

- Formulate a rule for when two straight lines are perpendicular.

- Test the rule for other straight lines.

Fig. 1 The function task (reformulated from Olsson (2018)) 
In this article, four student pairs will illuminate the two typical interaction-patterns. These pairs' interactions are presented in "Results."

\section{The linear function problem}

During the time of the study, three main tasks were given. The presented task (Fig. 1) facilitated the richest conversations. In these conversations, students more often anchored their arguments in mathematical properties (Lithner, 2017), such as the slope number being a varying parameter, and students more frequently engaged in all of the collaborative processes of building, monitoring, and repairing of their shared understanding (Roschelle \& Teasley, 1995).

The function tasks that were planned emphasized mathematical reasoning and nonroutine solving of tasks, where the struggle ought to be more like a challenge to solve, rather than an obstacle (Hiebert \& Grouws, 2007; Lithner, 2017; Stein et al., 2008). In order to facilitate a challenge easy to discuss, however not too difficult, tasks without a known procedure for the students to follow were emphasized. Therefore, students were likely not to withdraw from mathematical conversations due to differences in their level of competence in mathematics. The task presented in Fig. 1 had previously and successfully been tested for similar purpose at another school (Olsson, 2018).

An aim with this task was also to facilitate opportunities for the students to connect different function representations to construct their own solutions to the linear function problem. In connecting different function representations, such as graphical and algebraic representations, students can build a more comprehensive function concept (Best \& Bikner-Ahsbahs, 2017), rather than view functions as "topics" to be learned in isolation of the others" (Thompson, 1994, p. 24). The function concept is regarded in school mathematics as difficult for students to learn, but very important to understand, since it has a central role in organizing and connecting many mathematical ideas (Michelsen, 2006).

When students solved the function tasks, they were encouraged to use the dynamic software program GeoGebra, which may promote active investigation of different function representations (Olsson, 2019; Preiner, 2008). The strength of the program, to easily adjust representations in the algebraic field or the graphical field, gave students rapid feedback on well-justified suggestions or simple guesses. Students' engagement with GeoGebra for solving a function task may contribute to students' mathematical reasoning (Granberg \& Olsson, 2015) and, thus, their way of interacting. However, GeoGebra does not interpret the meaning. Students need to make their own meanings of their findings, which is important for students in producing their own mathematics. In this case study, the unit of analysis is the student-student interaction, unlike Olsson (2018) where GeoGebra additionally was included in the unit of analysis.

\section{Data analysis}

Video recordings of the eight students' talk and actions were viewed multiple times, and the first step of analysis comprised denoting longer sequences where students 
often made justifications and explanations anchored in mathematical properties as sequences of creative reasoning (CMR) (Lithner, 2017). These sequences were thus coded as CMR-sequences (creating a solution with plausible arguments anchored in mathematics) and further transcribed.

Then, a second analytical step comprised the coding of each student's utterance in the CMR-sequences with respect to collaborative processes (Roschelle \& Teasley, 1995). How a CMR sequence was coded for collaborative processes (see Table 2 for details) and for aspects of creative reasoning (see Table 1 for details) is exemplified in "Bi-directional interaction."

The third step in the analytical process was to provide a thick description (Powell et al., 2003) of the four pairs' collaboration and reasoning within their CMR sequences. This step enabled a description of students' participation in the collaborating dyads, which made it possible to characterize students' agency in their conversations as primary, secondary, or shared (Mueller et al., 2012). First, a description was made on the students' interactions when engaged in reasoning, concerning how they attempted to engage with each other. If students constructed a solution sequence where they connected ideas and thoughts making a shared understanding of the current situation, it was recognized as shared agency. If students engaged individually, clearly having different roles when suggesting ideas or explaining thoughts, their agency was recognized as primary or secondary. After characterizing students' interactions, it was possible to describe students' typical roles in their engagement connected to how they reasoned about linear functions and the ways they collaborated to solve the given task.

Tables 1,2, and 3 present an overview of characterization of codes for CMR, collaborative processes, and agency, respectively. The headings in the tables are the interactional categories, and the bullet points describe the interactional aspects within each category and were used as codes in the analysis. Excerpts in "Results" outline typical interactions found between the student pairs in their CMR sequences. The excerpts are chosen because of their clear interaction patterns.

\section{Results}

Studying students' interactional aspects of reasoning, collaborative processes, and agencies contributed to rich descriptions of students' participation, which further grew into two distinct ways of interacting in the conversation, here named bi-directional interaction and one-directional interaction. Characteristics for the bi-directional interaction were students who engaged with similar roles; mutually attempting to understand each other's ideas; making suggestions, listening, and negotiating mathematical properties; and mutually driving the problem solving process forward. Such interaction was found in the student pairs: Philip and Noah, and Emma and Hannah. Characteristics for the one-directional interaction were students who engaged with different roles and one student who led the conversation by being the primary reasoner and suggestion-maker for solving the problem, which a peer attempted to understand and occasionally contributed with input to the final outcome of a reasoning sequence. Such interaction was found in the student pairs: Olivia and Oscar, and Leah and Isaac. In the following excerpts, interactional aspects of 
reasoning, collaborative processes, and exercised agency are italicized followed by a number from the students' utterances in the conversations.

\section{Bi-directional interaction}

Philip and Noah had found instances for when two linear functions were perpendicular onto each other. In the challenge that followed, they attempted to make a rule explaining when the functions were perpendicular to each other.

\section{Excerpt 1}

\begin{tabular}{lll}
\hline 1 & Noah & $\begin{array}{l}\text { I don't know how we should write it [the rule], because... } \\
\text { Okay. It's slope number. What is it called? It's } m \ldots \text { (writ- } \\
\text { ing on the laptop) }\end{array}$ \\
3 & Philip & Yes \\
4 & Noah & Divided by 1, right. Then we'll have... \\
5 & Philip & No. One divided by $m$ is right \\
\hline
\end{tabular}

Noah stated a problem for formulating the rule, thus initiating a new focus in a process characterized as building (1). Philip responded by monitoring their problem when he asked what the slope number was called, which was answered by himself (2). In Philip's turn, he also built their shared understanding by suggesting a focus anchored in the slope number (2). Noah continued to build when he accepted the initiation of formulating the rule (3). Again, Philip continued to build when he suggested it was $m$ divided by 1 (4). This was not logical to Noah, and he disagreed with Philip's suggestion of the rule. Noah made a counter-suggestion: 1 divided by $m(5)$. Thus, Noah's countersuggestion can be seen as a repairing of their shared understanding. Together, Noah and Philip created a new reasoning sequence for making a rule based on the generalized slope number $m$.

To specify the coding procedure for this excerpt: The sequence was characterized as CMR (Lithner, 2017), because in the conversation students' reasoning was new to them when they created an expression for the rule. Their explanation involved a connection between the perpendicular functions which was anchored in the mathematical property of the slope number $m$. Their solution made sense to the student pair. Thus, it was plausible to them. Concerning their collaborative processes (Roschelle \& Teasley, 1995); students were, for instance, building a shared understanding when suggesting a focus of the rule anchored in the slope number, and repairing when making a countersuggestion to the rule.

In the further unfolding problem-solving path, the student pair continued in a turn-taking conversation. 


\section{Excerpt 2}

6 Philip Yeah, but is it a rule?

7 Noah Yes

8 Philip How we should say something, in a way

9 Noah A rule. Oh yeah. The slope number on one line is something in connection to the other line. I don't know how to formulate, explain it. (Pause)

You have the slope number for one [line] and slope number for the other one. To figure out the second one, I use that formula (pointing at the formula they have written down). So ...

10 Philip No, right. We need to figure out something better to say than the first and the second. Maybe like $a$ and $b$, or something

11 Noah Yes. I can try (writing on the laptop). Slope number for line $\mathbf{b}$ is $-m / 1$. Wait. -1 divided by the slope number for line $a$. We say that. At line $a$

12 Philip Yeah, but slope number (pointing at the screen). We can use $m$, as $m x+c$. Instead of "slope number." To add some subject content, concepts, with numbers and letters

Philip and Noah agreed upon the rule $-1 / m$. However, Philip was initially not sure whether it was a proper mathematical rule $(6,8)$. Noah explained his take on the meaning of a mathematical rule and attempted an explanation of the rule they had found (9). Noah was building their shared understanding by anchoring his reasoning on how two linear function's slope numbers were connected (9). Together both contributed to generalize their findings $(10,11)$ into a rule constructed from observations of pairs of perpendicular lines, which they emphasized as "subject content, concepts, with numbers and letters" (12). Their attempt to create a rule was co-constructed through their turn-taking conversation.

Thus, Noah and Philip were both actively participating in solving the problem by making suggestions, observing suggested strategies, taking initiatives, and making counter-suggestions. The students' line of thought in the excerpts is collaboratively built, and their reasoning is co-constructed and does not exist without the peer's input. Hence, Noah and Philip exercised shared agency creating arguments together through collaborative processes and CMR.

Emma and Hannah began their problem solving by testing different linear functions to be perpendicular to the line $y=4 x+2$. Their dialogue was focused on varying parameters (slope number and constant), and an anticipation where the lines would appear in the coordinate system. Excerpt 3 shows Emma and Hannah's continuing conversation and struggle about the connection between linear functions for being perpendicular. 


\section{Excerpt 3}

\begin{tabular}{|c|c|c|}
\hline 13 & Hannah & $y$ equals. I have Caps Lock on. Eh, what should we try? \\
\hline 14 & Emma & $x .1$ divided by $4 \ldots$ plus 2 \\
\hline 15 & Hannah & $\begin{array}{l}\text { No, it's not the same. I thought, if it were the same } \\
\text { [the rule could be] that we only put minus sign in the } \\
\text { front. But that doesn't work }\end{array}$ \\
\hline 16 & Emma & I don't know what we have been doing \\
\hline 17 & Hannah & $\begin{array}{l}\text { Wait. If we take } 4 \text { divided by minus... (writing on a } \\
\text { paper). No } \\
\text { We have. What we actually have been doing... We put } \\
\text { number } 4 \text { as the denominator in the fraction, in a } \\
\text { way. But I don't know }\end{array}$ \\
\hline
\end{tabular}

Emma and Hannah struggled to make sense of their own suggestions $(15,16,17)$. Hannah initiated a new sequence of guess and check, thus collaboratively building (13). Emma responded with further building when suggesting a new linear function: $y=1 / 4 x+2$ (14). Her suggestion conflicted with Hanna's expectation of perpendicularity of two linear functions (15). She thought that the pair of slope numbers should have been 4 and -4 . Hannah's correction, at least for herself, was about the conflicting interpretation of the connection between the linear functions (15). Thus, Hannah observed that what she had previously thought did not make sense, which is characterized as repairing their progress (15). Emma observed that their input did not result in a desired outcome, and she monitored their problem situation (16). Hannah continued monitoring by attempting a further explanation of the algebraic representation, stating indirectly that the slope number of one line was found as a denominator in the slope number of a perpendicular function (17). She vaguely suggested that it ought to be a negative slope number but rejected her own suggestion (17).

Emma and Hannah struggled actively together attempting to find a pair of perpendicular lines. Both students addressed the slope numbers of the perpendicular pair of linear functions, and their reasoning sequence was anchored in the mathematical property of the slope number, mainly referred to in the algebraic expressions. The students attempted in a joint effort to solve the linear problem with co-constructed reasoning. Therefore, their participation in the interaction, seen in the excerpt and before and after, is characterized as a shared agency.

The two pairs, Philip and Noah, and Emma and Hannah, typically attempted to make sense of each other's ideas and thoughts. Similar for both pairs were a joint effort and engagement in different aspects of working together: making suggestions, listening to one another, and expressing disagreement with actions or suggestions made by each other or oneself. Although the two collaborating pairs often were engaged in similar ways, Philip and Noah stood out when it came to working together through reasoning and engagement in all the collaborative processes. This pair more often entered processes of repairing of their shared understanding of the function problem, compared to Emma and Hanna. 


\section{One-directional interaction}

Olivia and Oscar were not engaged in a mutual exchange of ideas and actions for solving the function problem. In the following conversation Olivia and Oscar began their problem solving.

\section{Excerpt 4}

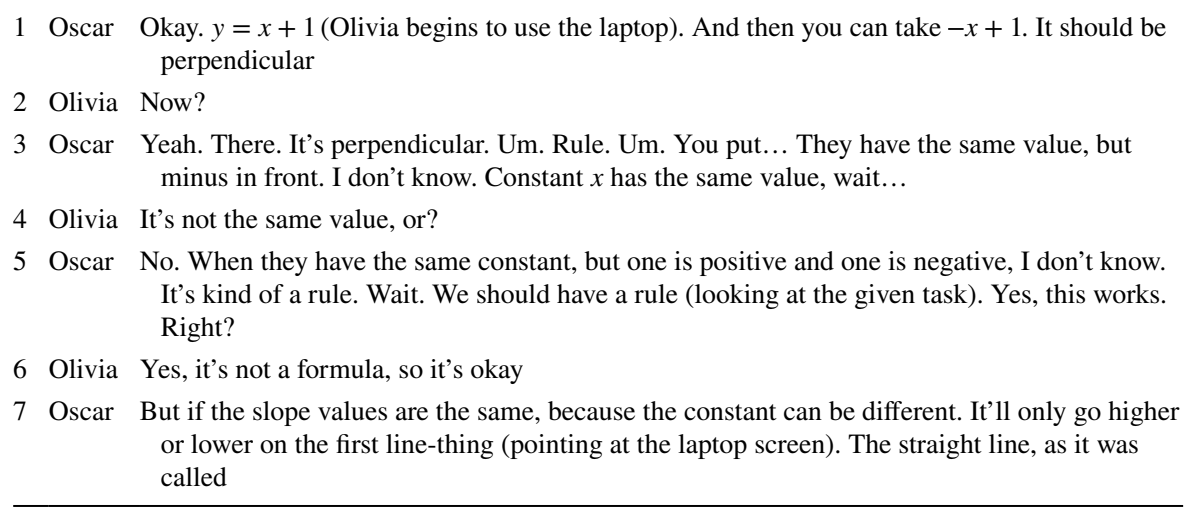

Oscar was the driving force for solving the problem. He made suggestions, such as $y$ equals $x+1$ and $-x+1$, and stated problems "They have same value, but minus in front... Constant $x$ has the same value" $(1,3)$. Oscar attempted an explanation about the observation of the linear functions, justified in the "constant $x$," which was plausible to him and anchored in mathematical property of the slope number ( 3 , 5). Olivia accepted Oscar's explanations and suggestions, by putting her own words to Oscar's ideas: "Yes, it is not a formula, so it's okay" (6) and later she said "Yes, the constant can be different, and it doesn't have to be the same." Thus, the students were suggesting and accepting, in the process of building.

Oscar and Olivia demonstrated the process of monitoring when Olivia asked if her input looked correct (2), and when she questioned the meaning of the numbers having same value (4). Oscar monitored when he attempted an explanation trying to say that the slope numbers should be the same numbers only with different signs (5). In his last statement, he differentiated between the slope number and the constant (7). Thus, Oscar expressed more details to their rule: the perpendicular lines had to have the same slope numbers with opposite signs and the constant could be arbitrary numbers.

From their interaction and way of participating, Oscar and Olivia had different roles in the building and monitoring process, which characterized their interactions throughout their problem-solving path. They did not have instances of repairing. Oscar exercised agency when suggesting and explaining his ideas. Thus, he was the initiator and primary agent of reasoning in the conversation. Olivia accepted Oscar's explanation of the rule, which she distinguished from a formula (6). Oscar further 
explained his thoughts, after Olivia's acknowledgement of his suggestions (7). Olivia was a secondary agent who contributed with trying to understand how Oscar was thinking and what she should do to execute his ideas into action in GeoGebra. Their student-student interaction did not demonstrate a mutual and synchronous way of making and maintaining a shared understanding of the problem. Nor did they exercise a shared agency for solving the problem.

Leah and Isaac found a set of linear functions making a perpendicular pair: $y=x+3$ and $y=-x+3$. They expressed a relation between the two linear functions: two opposite slope numbers, which they further referred to as either $-x$ and $x$, or -1 and +1 . They agreed upon this relation as the rule and Leah initiated testing of their rule for other linear functions.

\section{Excerpt 5}

\begin{tabular}{|c|c|c|}
\hline 8 & Isaac & $\begin{array}{l}\text { Okay. Then we create a line. We choose the line } y \text { equals, we choose } 2 x+3 \text {. } \\
\text { Okay. It's probably a bad number. Okay, and then for every } x \text { there is } 2 \text {. Then } \\
\text { the negative version of this should be } y=-2 x \text {, and then it should intersect... } \\
\text { (writes on the laptop) But it isn't going to... It's always minus... The line } \\
\text { should always be }-x \text {. Like that (writes on the laptop) }\end{array}$ \\
\hline 9 & Leah & Always? \\
\hline 10 & Isaac & Yes, because if I use $-2 x$, it doesn't work. $y=-x$ and it should intersect... \\
\hline 11 & Leah & 3 \\
\hline 12 & Isaac & Are you sure? \\
\hline 13 & Leah & Yes. Try (Isaac writes on the laptop) \\
\hline 14 & Isaac & Hmm. No. 4 \\
\hline 15 & Leah & Oh. It's... (Leah uses the laptop). It's because this is $\mathrm{f}^{* * *} \mathrm{ed}$ \\
\hline 16 & Isaac & Okay, but wait. It doesn't work for every number. Okay, we'll figure it out \\
\hline 17 & Leah & I think it's wrong to say it's always $-x$. Try minus... What did you use here? 2 ? \\
\hline 18 & Isaac & This is $2 x+3$ \\
\hline 19 & Leah & Then you should try $-2 x$. \\
\hline
\end{tabular}

Isaac contended for their new pair of linear functions that always one of the slope numbers had to be $-x$ (8). Leah questioned his statement (9), which Isaac replied to by pointing out the different variables $-2 x$ and $-x$ (10), which is likely his way of anchoring the reasoning in the mathematical property of the slope numbers being -2 and -1 . They further attempted to evaluate their input in GeoGebra (11-15). Towards the end of the turn-taking sequence, Isaac interpreted their observations with guessing and checking with GeoGebra and said that it did not work for every case (16). Leah repeated his observation and specified that a perpendicular line not always was $-x(17)$, meaning that for a pair of linear functions one line did not have to have a slope number equal to -1 . She continued building by suggesting $-2 x$ for a perpendicular line (19), which Isaac previously had observed would not result in a perpendicular line (10). 
In Leah and Isaac's conversation, there were mainly collaborative processes characterized as building by making suggestions for pairwise linear functions ( 8 , $10,13,18,19)$, which was monitored by observations, evaluations, and questions $(9,12,14,16)$. They did not engage in processes of repairing. Both students contributed to the problem-solving process; however, it was primarily Isaac that suggested and made arguments connected to mathematical properties anchored in the algebraic representation of the slope number. Isaac acted as the primary agent leading the conversation and making the final arguments. Leah, on the other hand, either built by accepting Isaac's ideas or monitored by questioning, repeating, and observing how Isaac's ideas and utterances played out in GeoGebra. Therefore, she exercised secondary agency.

In the interaction of the two pairs, Olivia and Oscar, and Leah and Isaac, only one student attempted to make sense of the collaborating peer's suggestions. Similar for both pairs were a mutual attempt to solve the function problem where they exercised different roles in the problem-solving session. Moreover, it was Oscar and Isaac who led the conversations, whereas Olivia and Leah attempted to understand their peers' thoughts and actions. The student pair Olivia and Oscar stood out compared to Leah and Isaac in the way that their roles in the interaction were more clearly divided in primary and secondary agency, particularly how Oscar made the reasoning sequences which Olivia tried to understand. The interplay in the interaction patterns found in their attempt of collaboration is in a clear contrast to, particularly, Philip and Noah's well-functioning collaboration.

\section{Discussion}

The study's research question is What are the patterns of interaction for creating a shared understanding through the interplay between students' creative reasoning, collaboration, and exercised agency in a mathematical problem-solving session?

The case study has analyzed videos of students' attempt to collaborate and engage in mathematical talk to solve a linear function problem. The findings reveal an interplay between exercised agency, reasoning, and collaborative processes, affecting how student-student interactions are expressed. Based on the students' roles in pairwise collaboration, considering interactional aspects, a pattern for their interaction evolved in the analysis process into bi-directional interaction and one-directional interaction.

If students exercise mutual attempts to understand one another (e.g., Mueller et al., 2012; Roschelle \& Teasley, 1995), using arguments logically, and anchored in mathematical properties of the reasoning sequence (Lithner, 2017), where both are the driving force of the problem-solving process, they are in a bi-directional interaction. Philip and Noah, and Hannah and Emma revealed such an interactional pattern. Students typically negotiated mathematical properties (Lithner, 2017) to make a pair of perpendicular lines, and they often represented functions dynamically. Students' active investigations of mathematics using GeoGebra is seen as support for students' reasoning and activity (e.g., Granberg \& Olsson, 2015; Olsson, 2019; Preiner, 2008), and observed in the two student pairs' engagement. Students expressed functions algebraically and graphically, thus, 
actively engaged with GeoGebra's feedback. Therefore, functions were not operated on as separate topics to be learned (Thompson, 1994), important for a deeper understanding of the function concept (Best \& Bikner-Ahsbahs, 2017).

Both student-pairs participated in turn-taking conversations (Sidnell, 2010) building on suggested and explained ideas (Alrø \& Skovsmose, 2004). Students exercised coordination and synchronicity in their interaction which characterizes "true" collaboration, where it is likely to achieve a shared understanding (Baker, 2015; Roschelle \& Teasley, 1995; Sarmiento \& Stahl, 2008).

Philip and Noah's interaction, viewed holistically, showed an interaction pattern where both students engaged in collaborative processes of building, monitoring, and repairing. When Philip and Noah engaged in a repairing process, they more often anchored their reasoning in mathematical properties of linear functions, compared to the other pairs. Moreover, Philip and Noah willingly shared ideas and entered situations with conflicting ideas (Dillenbourg, 1999), such as the formulation of the rule using the connection between an algebraic expression and a graphical representation of the function concept. In the mutual and synchronous interaction, Philip and Noah co-constructed reasoning sequences and participated with shared agency. Therefore, their agency co-existed with collaborative processes and creative reasoning important for shared understanding.

When students exercise different roles in the problem-solving process where the final outcome is expressed repeatedly by one of the students (Mueller et al., 2012), they are in a one-directional interaction. In such an interaction, this study suggests that, a primary agent utters creative reasoning, and a secondary agent listens or tries to understand a peer's argumentation. Thus, a student with a secondary agency rarely or never engages in creative reasoning. Moreover, their collaborative processes are characterized by building and monitoring instances, missing the important repairing instances valuable for a possible evolving of students' understanding.

Such a pattern was demonstrated in the student pairs Olivia and Oscar, and Leah and Isaac. In both pairs, one student led the process of solving the task. The coworking student often attempted to understand suggestions or explanations made by the primary agent. Thus, students engaged with different agencies. Here, Oscar and Isaac participated as the primary agents, and Olivia and Leah as the secondary agents. The secondary agents exercised their agency through expressed ideas and questions about the primary agents' ideas. Their input was either assimilated into the final outcome (Mueller et al., 2012) of the reasoning, or considered by the peer who refined the input or neglected it. Concerning collaborative processes for making a shared understanding (Roschelle \& Teasley, 1995): Olivia and Oscar or Isaac and Leah did not experience conflicting ideas. Even though they attempted to collaborate, they did not seem to have a shared understanding, and they rarely experienced discrepancies in their ideas, which they would have to repair.

Oscar expressed more details to the solution strategies, and anchored ideas in mathematics (Lithner, 2017) concerning aspects of the rule for making two linear functions perpendicular than the other primary agent Isaac, who often led the conversation and made suggestions for solving the problem. Both Olivia and Leah tried to understand how their peers were thinking. Consequentially, their student-student 
interaction was not a mutual and synchronous way of creating a shared understanding of the function problem.

Students who engage in a bi-directional or one-directional manner may change roles in a problem solving process (Child \& Shaw, 2016). A student might assimilate a peer's input to construct a final argument, which is in this study recognized as a primary agent (Mueller et al., 2012) in a one-directional interaction and as shared agency (Mueller et al., 2012) in a bi-directional interaction. Therefore, characteristics of "assimilating a peer's construct into a final argument" do not indicate what kind of agency a student has exercised. Therefore, to categorize the interactional aspect agency, it is important to study the collaborating pair's turn-takings and other interactional aspects at play, such as collaborative processes and mathematical reasoning.

\section{Concluding thoughts}

This study illuminates two interactional patterns from four student pairs: Noah and Philip, Hannah and Emma, Oscar and Olivia, and Leah and Isaac. The limitation of the small sample is acknowledged; however, rich descriptions and the detailed analysis have provided important insights in students' interactions when collaborating and reasoning about functions. More student pairs' interactions should be studied, and their engagement in a broader specter of mathematical problems, to further reveal nuances to interactional patterns found in students' attempt to collaborate and reason mathematically. Researching several instances of students' interactions in different settings may contribute to more nuances in how students, of different age, learning different mathematical topics, in different environments, develop their own mathematical voice (Schoenfeld, 2013; Sengupta-Irving, 2016).

If students interact in a dynamic way, as described above, where both participate in equal roles and show authority over mathematical ideas during the problemsolving process, they might construct a shared understanding from merging an interplay of ideas. Such dynamic structure of pairwise collaboration reveals important components in students' mathematical communication (Sidenvall, 2019), to better understand underlying mechanisms for fruitful collaboration (Child \& Shaw, 2018; Kuhn, 2015; Seidouvy \& Schindler, 2019). These identified conditions are both being promoters in a problem-solving process, both making reasoning anchored in mathematical properties, and both being engaged in different collaborative processes. Such an interactional pattern in a bi-directional interaction promotes learning of mathematics through quality interactions (Pijls and Dekker, 2011; Varhol et al., 2020).

The contrast to such a dynamic interplay is a monotonic one-directional interplay, where only one student evolves his or her individual problem space. In such instances of one-directional interaction, teacher involvement should be suggested for supporting both students to build (accept and suggest) and monitor (explain and ask question) emphasizing plausible and mathematically founded argumentation.

Reasons for the two patterns of interactions that occurred might have several explanations. One reason might be students' individual experiences and personalities. 
Comparing the student pairs in the study, the student pair Philip and Noah stood out and demonstrated a productive interaction, as described above and in results. It is likely that their individual personalities were a good match. Thus, affective patterns or individual personalities come into play and influence students' conversations (Cobb et al., 2009). Other influencing aspects are students' background and disposition for learning, self-confidence and past success in mathematics, and beliefs about their roles and roles of others (Mueller et al., 2012).

A second reason is the given task. Although the given task presents an opportunity for creative reasoning (Granberg and Olsson, 2015), it does not automatically initiate a productive engagement in the other interactional aspects of this study. To promote interactional aspects such as collaboration and agency, a mathematical problem might entail other features than explicitly discussing the slope number and constant in a linear function found in an algebraic and graphical expression. If an individual student has experienced constraints with mathematics, it might prevent them for further engaging in a productive social interaction with a peer. Therefore, it might be worthwhile considering a relatable or meaningful context for students to reason about, and for translating between function representations.

A third reason to consider is classroom norms and teacher involvement in students' interactions. Regarding the first aspect, classroom norms, Yackel and Cobb (1996) differentiate between a social norm as an expected explanation to a given task, whereas a sociomathematical norm is an acceptable mathematical explanation. Both aspects are important for individual and collective learning, and students' engagement in both would influence their pattern of interaction. The second aspect, teacher involvement, has the potential to provide students with necessary resources for social norms and sociomathematical norms. A study found that important teacher guidance for collaborative inquiry happens through supporting student contributions with well-defined structure for mathematical work (Staples, 2007).

An agenda for further research on the three mentioned reasons for the two interactional patterns could be studies of different tasks promoting CMR, collaborative processes, and exercising of shared agency. Another future study could focus on teacher guidance: opportunities and limitations with teacher actions for students' productive interactional pattern. A third study could include interviews with students focusing on individual variables, such as beliefs about one-self as a mathematics learner, self-confidence, and the role of the collaborating peer. A broader understanding of these influential aspects might give a more complete understanding of the underlying mechanisms for productive interactions through the interplay of collaborative processes, mathematical reasoning, and exercising of agency.

If a teacher observes such an interaction pattern, the teacher could facilitate a change of roles: a secondary agent attempts to suggest strategies and explain outcomes or connection anchored in mathematical properties. A teacher's awareness of interactional patterns concerning collaboration processes, reasoning, and agency, has the potential to contribute to students' fruitful interactional dynamic. Moreover, such teacher actions has the potential to model important aspects to facilitate students' synchronicity and coordination pooling knowledge together to construct their own mathematical knowledge for understanding mathematical ideas (Stockero et al., 2019). Therefore, further research on teacher's actions facilitating dynamic 
interactions between the peers, where students are exercising shared agency, might provide additional insights to foster students' learning of mathematics through quality interactions.

\section{Disclaimer}

The manuscript has not been submitted to more than one journal for simultaneous consideration.

The submitted work is original and is not published elsewhere in any form or language (partially or in full). This manuscript has not been split up into several parts. Results are presented clearly, honestly, and without fabrication, falsification, or inappropriate data manipulation.

No data, text, or theories by others are presented as if they were the author's own ("plagiarism"). Proper acknowledgements to other works have been given. The author had permissions for the use of software. Research articles have been cited appropriate and relevant literature in support of the claims made. Author has avoided untrue statements.

Funding Open Access funding provided by Norwegian University of Life Sciences This study was funded by a Ph.D. project.

Availability of data and material All data (video recordings, audio recordings, and logs) is securely stored in computer folders connected to the University.

Code availability NVivo was used for coding the videos. All coding procedures are securely stored.

\section{Compliance with ethical standards}

Conflict of interest The author declares that she has no competing interests.

Consent to participate The participating teachers and students were informed of the research purpose and gave written informed consent according to the ethical requirements of the Norwegian Research Council (The Research Council of Norway, 2018).

Open Access This article is licensed under a Creative Commons Attribution 4.0 International License, which permits use, sharing, adaptation, distribution and reproduction in any medium or format, as long as you give appropriate credit to the original author(s) and the source, provide a link to the Creative Commons licence, and indicate if changes were made. The images or other third party material in this article are included in the article's Creative Commons licence, unless indicated otherwise in a credit line to the material. If material is not included in the article's Creative Commons licence and your intended use is not permitted by statutory regulation or exceeds the permitted use, you will need to obtain permission directly from the copyright holder. To view a copy of this licence, visit http://creativecommons.org/ licenses/by/4.0/. 


\section{References}

Alrø, H., \& Skovsmose, O. (2004). Dialogic learning in collaborative investigation. Nordisk Matematikkdidaktikk, 9(2), 39-62.

Baker, M. J. (2015). Collaboration in collaborative learning. Interaction Studies, 16(3), 451-473. https:// doi.org/10.1075/is.16.3.05bak

Best, M., \& Bikner-Ahsbahs, A. (2017). The function concept at the transition to upper secondary school level: tasks for a situation of change. ZDM, 49(6), 865-880. https://doi.org/10.1007/s11858-017-0880-6

Boesen, J., Helenius, O., Bergqvist, E., Bergqvist, T., Lithner, J., Palm, T., \& Palmberg, B. (2014). Developing mathematical competence: from the intended to the enacted curriculum. The Journal of Mathematical Behavior, 33, 72-87. https://doi.org/10.1016/j.jmathb.2013.10.001

Carlsen, M., Erfjord, I., Hundeland, P. S., \& Monaghan, J. (2016). Kindergarten teachers' orchestration of mathematical activities afforded by technology: agency and mediation. Educational Studies in Mathematics, 93(1), 1-17. https://doi.org/10.1007/s10649-016-9692-9

Child, S., \& Shaw, S. (2016). Collaboration in the 21st century: implications for assessment. Research Matters: A Cambridge Assessment publication, 22, 17-22.

Child, S., \& Shaw, S. (2018). Towards an operational framework for establishing and assessing collaborative interactions. Research Papers in Education, 1-22. https://doi.org/10.1080/02671522.2018.1424928

Cobb, P., Gresalfi, M., \& Hodge, L. L. (2009). An interpretive scheme for analyzing the identities that students develop in mathematics classrooms. Journal for research in mathematics education, 40(1), 40-68.

Dillenbourg, P. (1999). What do you mean by collaborative learning? In P. Dillenbourg (Ed.), Collaborative-learning: cognitive and computational approaches (pp. 1-19). Oxford: Elsevier.

Dillenbourg, P., Baker, M. J., Blaye, A., \& O’Malley, C. (1996). The evolution of research on collaborative learning. In E. Spada \& P. Reiman (Eds.), Learning in humans and machine: towards an interdisciplinary learning science (pp. 189-211). Oxford: Elsevier.

Engle, R. A., \& Conant, F. R. (2002). Guiding principles for fostering productive disciplinary engagement: explaining an emergent argument in a community of learners classroom. Cognition and Instruction, 20(4), 399-483. https://doi.org/10.1207/S1532690XCI2004_1

Freudenthal, H. (1991). Revisiting mathematics: China lectures. Dordrecht: Kluwer Academic.

Granberg, C., \& Olsson, J. (2015). ICT-supported problem solving and collaborative creative reasoning: exploring linear functions using dynamic mathematics software. The Journal of Mathematical Behavior, 37, 48-62. https://doi.org/10.1016/j.jmathb.2014.11.001

Gresalfi, M., Martin, T., Hand, V., \& Greeno, J. (2009). Constructing competence: an analysis of student participation in the activity systems of mathematics classrooms. Educational Studies in Mathematics, 70(1), 49-70.

Hiebert, J., \& Grouws, D. A. (2007). The effects of classroom mathematics teaching on students' learning. In F. K. Lester (Ed.), Second handbook of research on mathematics teaching and learning (pp. 371-404). Charlotte, NC: Information Age Publishing.

Kuhn, D. (2015). Thinking together and alone. Educational researcher, 44(1), 46-53. https://doi. org/10.3102/0013189x15569530

Langer-Osuna, J. (2018). Exploring the central role of student authority relations in collaborative mathematics., 50(6), 1077-1087. https://doi.org/10.1007/s11858-018-0965-X

Lithner, J. (2008). A research framework for creative and imitative reasoning. Educational Studies in Mathematics, 67(3), 255-276.

Lithner, J. (2017). Principles for designing mathematical tasks that enhance imitative and creative reasoning. ZDM, 49(6), 937-949. https://doi.org/10.1007/s11858-017-0867-3

Martin, L., \& Towers, J. (2015). Growing mathematical understanding through collective image making, collective image having, and collective property noticing. Educational Studies in Mathematics, 88(1), 3-18. https://doi.org/10.1007/s10649-014-9552-4

Michelsen, C. (2006). Functions: a modelling tool in mathematics and science. ZDM, 38(3), 269-280. https://doi.org/10.1007/bf02652810

Mueller, M., Yankelewitz, D., \& Maher, C. (2012). A framework for analyzing the collaborative construction of arguments and its interplay with agency. Educational Studies in Mathematics, 80(3), 369-387. https://doi.org/10.1007/s10649-011-9354-x

Olsson, J. (2018). The contribution of reasoning to the utilization of feedback from software when solving mathematical problems. International Journal of Science and Mathematics Education, 16(4), 715-735. https://doi.org/10.1007/s10763-016-9795-x 
Olsson, J. (2019). Relations between task design and students' utilization of GeoGebra. Digital Experiences in Mathematics Education, 5, 223-251. https://doi.org/10.1007/s40751-019-00051-6

Pijls, M., \& Dekker, R. (2011). Students discussing their mathematical ideas: the role of the teacher. Mathematics Education Research Journal, 23(4), 379-396. https://doi.org/10.1007/s13394-011-0022-3

Powell, A., Francisco, J., \& Maher, C. (2003). An analytical model for studying the development of learners' mathematical ideas and reasoning using videotape data. The Journal of Mathematical Behavior, 22(4), 405-435. https://doi.org/10.1016/j.jmathb.2003.09.002

Preiner, J. (2008). Introducing dynamic mathematics software to mathematics teachers: the case of GeoGebra. (PhD thesis), University of Salzburg, Austria. Retrieved from http://www.pucrs.br/ciencias/viali/ tic_literatura/teses/Preiner_Judith.pdf

Roschelle, J., \& Teasley, S. D. (1995). The construction of shared knowledge in collaborative problem solving. In C. O’Malley (Ed.), Computer supported collaborative learning (Vol. 128, pp. 69-97). NATO ASI Series (Series F: Computer and Systems Sciences): Springer, Berlin, Heidelberg.

Sarmiento, J. W., \& Stahl, G. (2008). Extending the joint problem space: time and sequences as essential features of knowledge building. In G. Kanselaar, Jonker, V., Kirschner, P. A., \& Prins, F. J. (Ed.), International perspectives in the learning sciences: creating a learning world. Proceedings of the Eighth International Conference for the Learning Sciences - ICLS 2008 (Vol. 2, pp. 295-302). Utrecht, The Netherlands: International Society of the Learning Sciences.

Schoenfeld, A. (2013). Classroom observations in theory and practice. ZDM, 45(4), 607-621. https://doi. org/10.1007/s11858-012-0483-1

Seidouvy, A., \& Schindler, M. (2019). An inferentialist account of students' collaboration in mathematics education. Mathematics Education Research Journal. https://doi.org/10.1007/s13394-019-00267-0

Sengupta-Irving, T. (2016). Doing things: organizing for agency in mathematical learning. The Journal of Mathematical Behavior, 41, 210-218. https://doi.org/10.1016/j.jmathb.2015.10.001

Sidenvall, J. (2019). Literature review of mathematics teaching design for problem solving and reasoning. Nordic Studies in Mathematics Education, 24(1), 51-74.

Sidnell, J. (2010). Conversation analysis: an introduction. Oxford: Wiley-Blackwell.

Stake, R. E. (2003). Case Studies. In N. K. Denzin \& Y. S. Lincoln (Eds.), Strategies of qualitative inquiry (2nd ed., pp. 134-164). Thousand Oaks, CA: Sage.

Staples, M. (2007). Supporting whole-class collaborative inquiry in a secondary mathematics classroom. Cognition and Instruction, 25(2-3), 161-217. https://doi.org/10.1080/07370000701301125

Stein, M. K., Engle, R. A., Smith, M. S., \& Hughes, E. K. (2008). Orchestrating productive mathematical discussions: five practices for helping teachers move beyond show and tell. Mathematical Thinking and Learning, 10(4), 313-340. https://doi.org/10.1080/10986060802229675

Stockero, S. L., Leatham, K. R., Ochieng, M. A., Van Zoest, L. R., \& Peterson, B. E. (2019). Teachers' orientations toward using student mathematical thinking as a resource during whole-class discussion. Journal of Mathematics Teacher Education, 1-31. https://doi.org/10.1007/s10857-018-09421-0

Thompson, P. W. (1994). Students, functions, and the undergraduate curriculum. Research in collegiate mathematics education, 1, 21-44. https://doi.org/10.1090/cbmath/004/02

van de Pol, J., Mercer, N., \& Volman, M. (2018). Scaffolding student understanding in small-group work. Journal of the Learning Sciences, 28(2), 1-34. https://doi.org/10.1080/10508406.2018.1522258

Varhol, A., Drageset, O. G., \& Hansen, M. N. (2020). Discovering key interactions. How student interactions relate to progress in mathematical generalization. Mathematics Education Research Journal. https://doi.org/10.1007/s13394-020-00308-z

Yackel, E. (2001). Explanation, justification and argumentation in mathematics classrooms. In M. van den Heuvel-Panhuizen (Ed.), Proceedings of the 25th International Conference for the Psychology of Mathematics Education (Vol. 1, pp. 9-24). Utrecht, The Netherlands.

Yackel, E., \& Cobb, P. (1996). Sociomathematical norms, argumentation, and autonomy in mathematics. Journal for research in mathematics education, 27(4), 458-477. https://doi.org/10.2307/749877

Publisher's Note Springer Nature remains neutral with regard to jurisdictional claims in published maps and institutional affiliations.

Ellen Kristine Solbrekke Hansen is a Ph.D. student in Mathematics Education. Her research interests include students' mathematical reasoning, collaborative work, and the role of the teacher supporting students' learning. Prior to undertaking the Ph.D., she worked as an upper secondary mathematics teacher. Ellen Kristine Solbrekke Hansen has a Master's Degree in Mathematics Education from 2011. 